Int. J. Electrochem. Sci., 12 (2017) 2495 - 2505

International Journal of

ELECTROCHEMICAL

SCIENCE

www.electrochemsci.org

\title{
Depassivation-repassivation Behavior of a CoCrMo Alloy under Tribological Contact in Simulated Body Fluids
}

\author{
Xinyi $\mathrm{Li}^{1}$, Yu Yan ${ }^{1, *}$, Haijun Zhang ${ }^{2}$, Yanjing Su ${ }^{1}$, Lijie Qiao ${ }^{1}$ \\ ${ }^{1}$ Corrosion and Protection Center, Key Laboratory for Environmental Fracture (MOE), Institute of \\ Advanced Materials and Technology, University of Science and Technology Beijing, Beijing 100083, \\ P.R.China \\ ${ }^{2}$ Shandong Rientech Medical Tech Co., Ltd., Branden Industrial Park, Qihe Economic \& Development \\ Zone, 251100, Qihe, Shandong Province, P.R. China \\ "E-mail: yanyu@ustb.edu.cn
}

doi: $10.20964 / 2017.03 .67$

Received: 5 January 2017 / Accepted: 30 January 2017 / Published: 12 February 2017

The long term performance of CoCrMo alloys in a tribocorrosive environment relies on the passivation properties of such alloys. The depassivation-repassivation phenomenon of CoCrMo alloy surfaces in a $0.9 \% \mathrm{NaCl}$ solution, with and without the addition of Bovine Serum Albumin (BSA), was investigated. The relationships between the wear-induced-depassivation rate (D), applied load (F) and stroke frequency (f) were deduced. These can be summarised as $\mathrm{D}=7.57 \mathrm{E}-6 \mathrm{~F} 0.56 \mathrm{f}$ in a $0.9 \% \mathrm{NaCl}$ solution and $\mathrm{D}=2.31 \mathrm{E}-6 \mathrm{~F} 0.85 \mathrm{f}$ in BSA containing solution. It was found that the ratio of the $\mathrm{Cr}$ element in the outer layer of the passive film was lower after depassivation. The passive film formed initially has better stability, which results in a lower depassivation rate in the initial few cycles compared with later cycles (relatively stable) in $0.9 \% \mathrm{NaCl}$ solution. The adsorption of BSA and the effects of mechanical wear result in a higher depassivation rate in the initial a couple of cycles in BAS containing $0.9 \% \mathrm{NaCl}$ solution.

Keywords: tribocorrosion; depassivation; repassivation

\section{$\underline{\text { FULL TEXT }}$}

(C) 2017 The Authors. Published by ESG (www.electrochemsci.org). This article is an open access article distributed under the terms and conditions of the Creative Commons Attribution license (http://creativecommons.org/licenses/by/4.0/). 